\title{
ESTUDO DE CASO: INTERDIÇÃO DEVIDO ÀS MANIFESTAÇÕES PATOLÓGICAS APARENTES EM UMA OBRA NA CIDADE DE CASCAVEL - PR
}

\author{
PAGANIN, RICARDO \\ Engenheiro Civil \\ Centro Universitário Assis Gurgacz \\ Paraná; Brasil \\ engpaganin@gmail.com \\ FELTEN, DÉBORA \\ Engenheira Civil \\ Centro Universitário Assis Gurgacz \\ Paraná; Brasil \\ deboraf@fag.edu.br
}

\author{
WENDT, VANESSA \\ Engenheira Civil \\ Centro Universitário Assis Gurgacz \\ Paraná; Brasil \\ vanewendt@hotmail.com
}

\author{
ADAME, KARINA SANDERSON \\ Engenheira Química \\ Centro Universitário Assis Gurgacz \\ Paraná; Brasil \\ ksanderson@fag.edu.br
}

\section{RESUMO}

As manifestações patológicas são caracterizadas por ocorrência de fissuras, deslocamentos, infiltrações e diversas outras situações que podem ter origem na execução, projeto ou utilização da edificação. O objetivo do presente trabalho foi identificar as prováveis causas das manifestações patológicas em um salão paroquial localizado na cidade de CascavelPR, classificar o grau de risco e, por meio do mesmo, propor um reparo para manifestações de grau de risco elevado. Utilizou-se a metodologia quantitativa, qualitativa e descritiva, nas quais os dados obtidos na visita ao local foram classificados e analisados por meio de pesquisa bibliográfica e após análise do grau de risco, a qual foi desenvolvida com a metodologia GUT (Gravidade, Urgência e Tendência), obteve-se um posicionamento sobre a proposta de reparo. As manifestações de maior incidência não foram as de maior gravidade, visto que um ponto de recalque ocasionou maiores danos à edificação do que diversos pontos de fissuras mapeadas. A análise resultou em 13\% das anomalias sendo de recalque, a menor porcentagem do estudo, porém, de maior gravidade, já as anomalias provenientes de dilatação dos materiais ocuparam 56\% do total das manifestações patológicas encontradas na edificação, seguidas pelas fissuras mapeadas com um total de $31 \%$. A proposta de reparo foi adotada visando a solução total dos problemas patológicos identificados no local.

Palavras-chave: recalque, reparo, recuperação, estrutural.

\begin{abstract}
Pathological manifestations are characterized by the occurrence of cracks, displacements, infiltrations and various other situations that may originate in the execution, design or use of the building. The objective of the present study was to identify as probable causes of pathological manifestations in a parish hall located in the city of Cascavel-PR, to classify the degree of risk and, through it, to propose a repair for manifestations of high risk degree. It used a quantitative, qualitative and descriptive methodology, in which the data displayed during the site visit were classified and analyzed through bibliographic research and after risk degree analysis, which was developed with the GUT (Gravity, Urgency and Tendency) methodology. ), use a placement on a repair proposal. As manifestations of higher incidence were not as of greater severity, since a return point caused greater damage to the editing of several mapped fissure points. An analysis resulted in $13 \%$ of the anomalies being repressed, the lowest percentage of study, but the highest severity, as already anomalies. $31 \%$. A proposed repair proposal was the same as the one adopted, since it was strictly technical and proposed a complete solution of the pathological problems applied on site.
\end{abstract}

Keywords: repression, repair, recovery, structural.

\section{INTRODUÇÃO}

Gomide, Fagundes e Gullo (2015) citam a importância em realizar vistoria nas edificações, como serviço paralelo de controle a cada etapa construtiva, a fim de evitar execução incorreta das etapas da obra e, consequentemente, o aparecimento de manifestações patológicas e prejuízos. Na grande maioria dos casos, a vistoria só é contratada quando a não conformidade já vem causando prejuízos. 
Para Thomaz (1989), manifestações patológicas são caracterizadas como ocorrência de fissuras, destacamentos, infiltrações, deslocamentos da edificação e podem ser consequência da execução de edificações, visto que podem ocorrer erros no ato da execução devido à ausência de mão de obra treinada e qualificada, deficiência na fiscalização da execução, projetos incompatíveis e/ou mal detalhados, características dos materiais e até mesmo da utilização.

Souza e Ripper (1998) referenciam qual seria a origem das manifestações patológicas em estruturas de concreto, levando em consideração diversos estudos feitos por diversos autores e chegam à conclusão de que a origem dos problemas patológicos se dá, em geral, na fase final do projeto de engenharia, ou seja, na execução do anteprojeto ou do projeto de execução.

De acordo com Helene (1992), é necessário realizar um diagnóstico completo, o qual deve levar em consideração as consequências das manifestações patológicas na estrutura como um todo, sendo as considerações divididas em dois tipos: as que afetam as condições de segurança da estrutura e as que comprometem o funcionamento e utilização da edificação. Em geral, as manifestações patológicas tendem a se agravar com o passar do tempo, podendo levar a danos maiores.

Levando tais fatos em consideração, é de extrema importância o diagnóstico correto das manifestações patológicas a fim de prevenir maiores danos. Vale ressaltar a importância da cautela aliada ao conhecimento técnico do profissional que avalia a situação da obra, onde em casos de risco a segurança dos usuários, a mesma deve ser interditada até que o reparo seja totalmente executado e a edificação esteja liberada para uso novamente.

Com esse trabalho, avaliou-se a situação do Salão Paroquial da Paróquia São Pedro Apóstolo, na cidade de Cascavel $\mathrm{PR}$, pois o mesmo encontrava-se interditado, a fim de verificar as prováveis causas que levaram à interdição e as possíveis ações necessárias para que a edificação volte a ser utilizada com segurança.

\section{METODOLOGIA}

\subsection{Tipo de estudo e desenvolvimento metodológico}

A pesquisa desenvolvida tratou de forma qualitativa, quantitativa e descritiva os temas abordados. Sendo qualitativa, pois avaliou-se cada problema, identificando o risco que o mesmo gerou para a edificação. De acordo com Goldenberg (1997) a pesquisa qualitativa leva em consideração a compreensão mais ampla de determinado assunto, mas não avalia os dados de acordo com representatividade numérica. Quantitativa, pois todos os problemas foram levantados e quantificados, de acordo com Fonseca (2002) a metodologia quantitativa é caracterizada por sua objetividade, se baseia na linguagem matemática, onde de fato quantifica os dados a fim de descrever um fato. $\mathrm{O}$ autor também enfatiza a importância de aliar a metodologia quantitativa com a qualitativa, onde é possível obter uma quantidade maior de dados que seriam obtidos utilizando as duas metodologias isoladas.

E por fim, descritiva, pois as situações mais relevantes foram abordadas especificadamente e discutidas de maneira específica em cada item. A metodologia descritiva é utilizada para as pesquisas que visam estudar a correlação entre diferentes variáveis, no caso deste trabalho avalia a manifestação patológica e correlaciona as possíveis causas e origens das mesmas.

Os dados foram levantados a partir de inspeção visual por meio da vistoria do objeto da pesquisa, com a finalidade de levantar e estudar as manifestações patológicas presentes na estrutura do salão paroquial, localizado na cidade de Cascavel - PR.

Após a visita in loco, optou-se pelo mapeamento das manifestações patológicas identificadas, assim como pela pesquisa bibliográfica para que os objetivos do trabalho pudessem ser atingidos conforme fluxograma da Figura 1. 


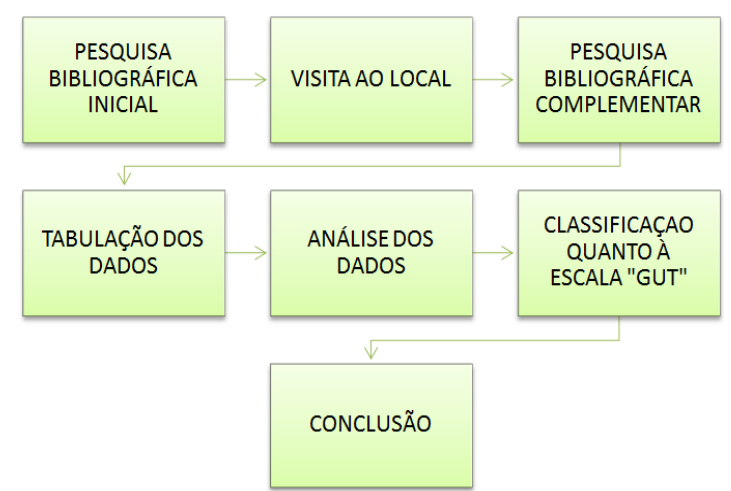

Figura 1: Fluxograma metodológico utilizado para o desenvolvimento da pesquisa.

Com a identificação dos problemas, realizou-se a tabulação dos dados, análise dos mesmos e classificação dos casos identificados de acordo com a metodologia GUT (Gravidade, Tendência e Urgência), para que assim pudesse ser realizada a conclusão do trabalho.

\subsection{Caracterização da edificação}

O levantamento foi realizado em um salão paroquial localizado no bairro Alto Alegre, na cidade de Cascavel - PR, conforme a Figura 2. O lote no qual realizou-se o estudo de caso possui outras edificações além da edificação inspecionada, sendo elas uma Igreja, a secretaria da igreja e um abrigo paroquial, no entanto, o estudo foi restrito às manifestações patológicas existentes no salão paroquial.

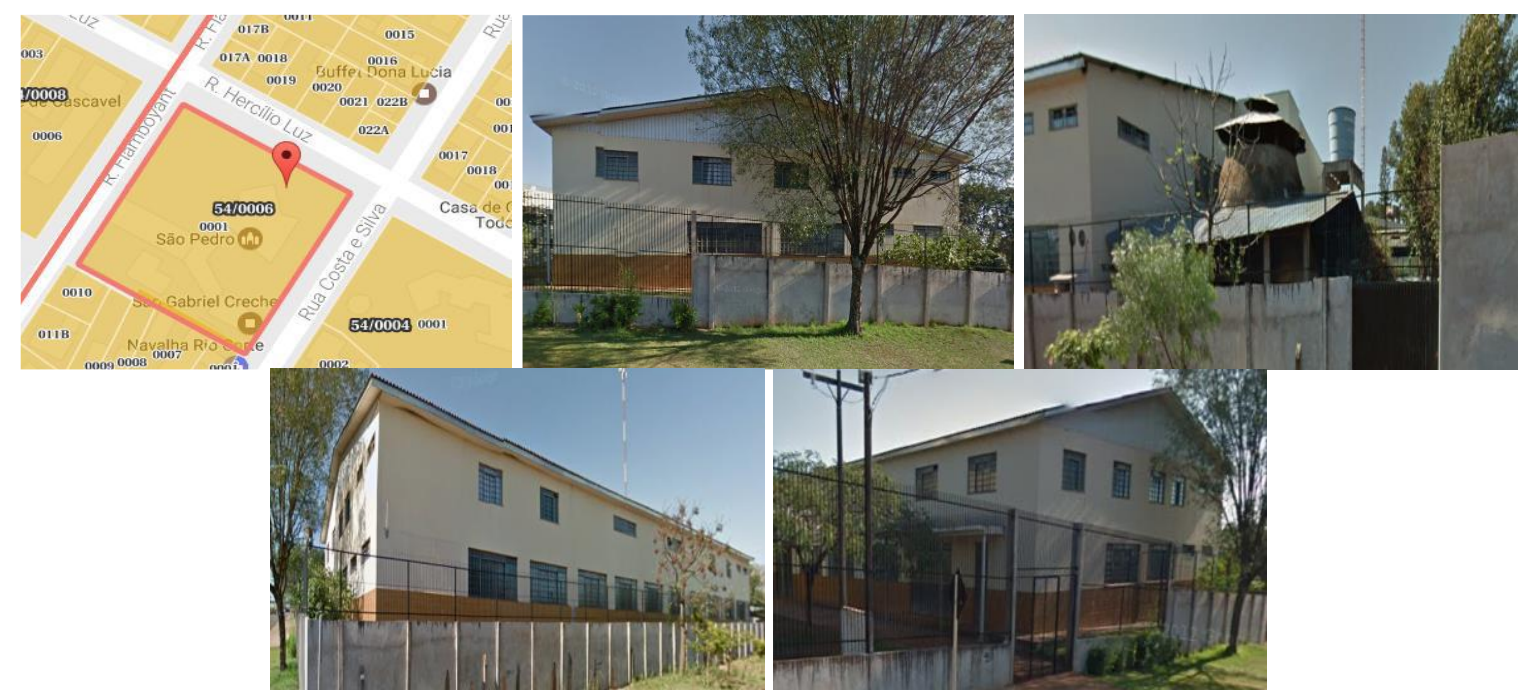

Figura 2: Localização e fachadas da edificação objeto da pesquisa.

Fonte: GEOPortal (2017).

O salão paroquial foi construído no ano de 2002, possui estrutura de concreto armado pré-moldada e vedações e divisões de alvenaria convencional, não possui projeto arquitetônico, estrutural e demais complementares e, além disso, a execução não foi acompanhada por profissional habilitado para tal, desde a execução não houveram intervenções na edificação. A edificação possui área de $1.740,72 \mathrm{~m}^{2}$, onde estão localizados dois mezaninos, um em cada extremidade do salão, o qual possui formato retangular. A edificação possui dois banheiros femininos, dois banheiros masculinos, um lavabo, um bar, uma cozinha e uma área de festas.

O mezanino do lado direito possui oito salas de aulas, as quais são utilizadas para catequese, com uma área de 268,51 $\mathrm{m}^{2}$ e o mezanino do lado esquerdo possui oito quartos, os quais são utilizados para realização de retiros paroquiais, com área de 329,06 $\mathrm{m}^{2}$. O mezanino direito, os dois banheiros femininos e os dois banheiros masculinos foram interditados devido à alegação de comprometimento estrutural segundo um profissional de engenharia que acompanha a situação. 


\subsection{Instrumentos e procedimentos para coleta de dados}

O levantamento dos dados foi realizado por meio de inspeção visual in loco, onde foram realizadas vistorias técnicas no salão paroquial no período entre maio e julho de 2017.

A priori, as anomalias foram analisadas visualmente para posteriormente serem fotografadas. Para a coleta de dados foram utilizados os seguintes materiais:

$>$ Câmera fotográfica digital, CANON EOS 5D;

$>$ Marreta;

$>$ Talhadeira;

$>$ Trena;

$>$ Escada.

Nas vistorias foram levantados todos os dados (localização, tipologia, extensão, características) necessários referentes às manifestações patológicas, as quais foram identificadas, classificadas e, em alguns casos; receberam uma proposta de reparo estrutural.

\subsection{Instrumentos e procedimentos para coleta de dados}

Após o levantamento dos dados, foi realizada a identificação de cada manifestação patológica por meio de revisão bibliográfica e da mesma forma, foram caracterizadas a gravidade e as prováveis causas e origens das manifestações patológicas, a fim de propor uma solução de reparo para os problemas de risco elevado. Os dados levantados foram tabulados e representados por meio de gráficos de frequência das manifestações patológicas. As mesmas foram classificadas quanto ao risco que apresentavam à estrutura da edificação de acordo com o método GUT (Gravidade, Urgência e Tendência).

O método GUT foi elaborado por Kepner e Tregoe (1991) e de acordo com os autores pode ser utilizado para classificar dados diversos. Sua metodologia consiste em contribuir para a tomada de decisões conforme a prioridade que se estabelece com a classificação, no qual é possível analisar os dados e elaborar uma matriz que leva em conta a gravidade, urgência e tendência (GUT).

Para avaliar a gravidade, leva-se em consideração a intensidade do dano, classificando numa escala de 1 (um) a 5 (cinco), em que 1(um) é considerado sem gravidade e 5 (cinco) extremamente grave. A urgência é determinada de acordo com a rapidez com a qual o dano deve ser reparado, para não causar maiores danos ou prejuízos, sendo classificado, também, numa escala de 1 (um) a 5 (cinco), em que 1(um) indica que não tem pressa para reparar o dano e 5 (cinco) pede ação imediata contra o dano. A avaliação da tendência se dá por uma escala de 1 (um) a 5 (cinco), igualmente feito com a gravidade e a urgência, e leva em consideração o comportamento do dano ao longo do tempo, sendo 1 (um) classificado como um dano estável, ou seja, não vai piorar e 5 (cinco) como um dano totalmente instável, o qual pode piorar rapidamente. Os itens citados, inclusive a escala de classificação de gravidade, podem ser visualizados na Figura 3.

\begin{tabular}{|l|l|l|}
\hline \multicolumn{1}{|c|}{ GRAVIDADE } & \multicolumn{1}{c|}{ URGÊNCIA } & \multicolumn{1}{c|}{ TENDÊNCIA } \\
\hline 1 = SEM GRAVIDADE & 1 = NÃO TEM PRESSA & 1 = NÃO VAI PIORAR \\
\hline 2 = POUCO GRAVE & 2 = PODE ESPERAR UM POUCO & 2 = VAI PIORAR EM LONGO PRAZO \\
\hline 3 = GRAVE & 3 = O MAIS CEDO POSSÍVEL & 3 = VAI PIORAR EM MÉDIO PRAZO \\
\hline 4 = MUITO GRAVE & 4 = COM ALGUMA URGÊNCIA & 4 = VAI PIORAR EM POUCO TEMPO \\
\hline 5 = EXTREMAMENTE GRAVE & 5 = AÇÃO IMEDIATA & 5 = VAI PIORAR RAPIDAMENTE \\
\hline
\end{tabular}

Figura 3: Classificação de gravidade, urgência e tendência da metodologia GUT.

Após avaliar os dados conforme sua gravidade, urgência e tendência, foi elaborada uma matriz, na qual faz-se a multiplicação dos resultados obtidos para cada item, em cada dado. $\mathrm{O}$ valor total obtido pela multiplicação de GxUxT revela a prioridade de reparo dos danos, considerando que o problema de maior valor será o que necessita a primeira atenção.

\section{ANÁLISES E DISCUSSÕES}

\subsection{Visita ao local}


$\mathrm{Na}$ vistoria do local foram encontradas inúmeras anomalias, as quais foram quantificadas por meio da Tabela 1 . As anomalias predominantes foram as fissuras, as quais possuem causas distintas e serão discutidas no decorrer do trabalho.

Tabela 1 - Resumo geral das manifestações patológicas identificadas

\begin{tabular}{|c|c|c|c|}
\hline AMBIENTE & $\begin{array}{l}\text { MANIFESTAÇÃO } \\
\text { PATOLÓGICA }\end{array}$ & OBSERVAÇÃO & $\begin{array}{l}\text { POSSÍVEIS } \\
\text { CAUSAS }\end{array}$ \\
\hline Fachada & Fissura & $\begin{array}{c}\text { Fissura com inclinação a } 45 \text { graus, acompanhando } \\
\text { extensão da parede e ultrapassando para a parede } \\
\text { transversal }\end{array}$ & $\begin{array}{l}\text { Recalque } \\
\text { diferencial }\end{array}$ \\
\hline $\begin{array}{l}\text { Consolos dos } \\
\text { pilares pré- } \\
\text { moldados }\end{array}$ & Fissura & Fissura nos consolos dos pilares no ponto de recalque & $\begin{array}{l}\text { Recalque } \\
\text { diferencial }\end{array}$ \\
\hline $\begin{array}{l}\text { Fachada } \\
\text { oeste - lateral } \\
\text { esquerda da } \\
\text { porta P3 }\end{array}$ & Fissura & Fissura vertical na lateral do pilar pré-moldado & $\begin{array}{l}\text { Movimentações } \\
\text { diferenciais }\end{array}$ \\
\hline $\begin{array}{c}\text { Fachada } \\
\text { oeste - lateral } \\
\text { direita da } \\
\text { porta P3 }\end{array}$ & Fissura & Fissura vertical na lateral do pilar pré-moldado & $\begin{array}{c}\text { Movimentações } \\
\text { diferenciais }\end{array}$ \\
\hline $\begin{array}{l}\text { Marquise } \\
\text { das portas } \\
\text { P1 e P2 }\end{array}$ & Fissura & $\begin{array}{l}\text { Fissura horizontal acompanhando toda a extensão da } \\
\text { marquise }\end{array}$ & $\begin{array}{c}\text { Movimentações } \\
\text { diferenciais }\end{array}$ \\
\hline $\begin{array}{l}\text { Marquise da } \\
\text { porta } \mathbf{P 2}\end{array}$ & Fissura & Fissura horizontal na laje da marquise & $\begin{array}{l}\text { Movimentações } \\
\text { diferenciais }\end{array}$ \\
\hline $\begin{array}{l}\text { Marquise da } \\
\text { porta P1 }\end{array}$ & Fissura & $\begin{array}{l}\text { Fissura horizontal com acompanhamento vertical, na } \\
\text { junção entre pilar/viga e alvenaria }\end{array}$ & $\begin{array}{l}\text { Movimentações } \\
\text { diferenciais }\end{array}$ \\
\hline $\begin{array}{l}\text { Marquise da } \\
\text { porta } P 3\end{array}$ & Fissura & $\begin{array}{c}\text { Fissura horizontal acompanhando toda a extensão da } \\
\text { marquise }\end{array}$ & $\begin{array}{l}\text { Movimentações } \\
\text { diferenciais }\end{array}$ \\
\hline $\begin{array}{l}\text { Lateral } \\
\text { direita da } \\
\text { porta } \mathbf{P 4}\end{array}$ & Fissura & Fissura vertical na junção entre pilar e alvenaria & $\begin{array}{c}\text { Movimentações } \\
\text { diferenciais }\end{array}$ \\
\hline $\begin{array}{l}\text { Marquise da } \\
\text { porta } P 4\end{array}$ & Fissura & $\begin{array}{l}\text { Fissura horizontal acompanhando toda a extensão da } \\
\text { marquise }\end{array}$ & $\begin{array}{c}\text { Movimentações } \\
\text { diferenciais }\end{array}$ \\
\hline $\begin{array}{l}\text { Entre janela } \\
\text { e marquise } \\
\text { da porta } P 3\end{array}$ & Fissura & Fissura horizontal com leve inclinação no canto direito & $\begin{array}{l}\text { Movimentações } \\
\text { diferenciais }\end{array}$ \\
\hline $\begin{array}{l}\text { Acima da } \\
\text { porta } P 4\end{array}$ & Fissura & Fissura horizontal com processo de infiltração & $\begin{array}{l}\text { Movimentações } \\
\text { diferenciais }\end{array}$ \\
\hline $\begin{array}{l}\text { Entre porta e } \\
\text { janela } \\
\text { (portas P1, } \\
\text { P2 e P3) }\end{array}$ & $\begin{array}{l}\text { Mapeamento de } \\
\text { reboco }\end{array}$ & $\begin{array}{l}\text { Mapeamento de reboco/textura com processo de } \\
\text { infiltração }\end{array}$ & $\begin{array}{l}\text { Retração da } \\
\text { argamassa }\end{array}$ \\
\hline $\begin{array}{l}\text { Acima da } \\
\text { porta P3 }\end{array}$ & $\begin{array}{l}\text { Mapeamento de } \\
\text { reboco }\end{array}$ & $\begin{array}{l}\text { Manchas de infiltração de água através da marquise e do } \\
\text { mapeamento de reboco }\end{array}$ & $\begin{array}{l}\text { Retração da } \\
\text { argamassa }\end{array}$ \\
\hline $\begin{array}{l}\text { Entre porta e } \\
\text { janela } \\
\text { (portas P1, } \\
\text { P2 e P3) }\end{array}$ & $\begin{array}{l}\text { Mapeamento de } \\
\text { reboco }\end{array}$ & $\begin{array}{l}\text { Mapeamento de reboco/textura com processo de } \\
\text { infiltração e apodrecimento }\end{array}$ & $\begin{array}{l}\text { Retração da } \\
\text { argamassa }\end{array}$ \\
\hline $\begin{array}{c}\text { Acima da } \\
\text { porta } P 4 \text { e na } \\
\text { marquise }\end{array}$ & $\begin{array}{l}\text { Mapeamento de } \\
\text { reboco }\end{array}$ & $\begin{array}{c}\text { Manchas de infiltração de água através da marquise e do } \\
\text { mapeamento de reboco }\end{array}$ & $\begin{array}{c}\text { Retração da } \\
\text { argamassa }\end{array}$ \\
\hline $\begin{array}{c}\text { Fachada } \\
\text { lateral }\end{array}$ & $\begin{array}{l}\text { Mapeamento de } \\
\text { reboco }\end{array}$ & Ao longo de toda a fachada & $\begin{array}{c}\text { Retração da } \\
\text { argamassa }\end{array}$ \\
\hline
\end{tabular}


Da mesma forma, observou-se também a presença de infiltrações, oxidação das esquadrias em alumínio, fissuras com mapeamento de reboco, ausência de impermeabilização em marquises e desconformidade na instalação das pingadeiras das janelas.

Após a realização da vistoria do local e da observação das manifestações patológicas, pode-se então elaborar o mapeamento dos problemas patológicos presentes na edificação, o qual pode ser observado na Figura 4.

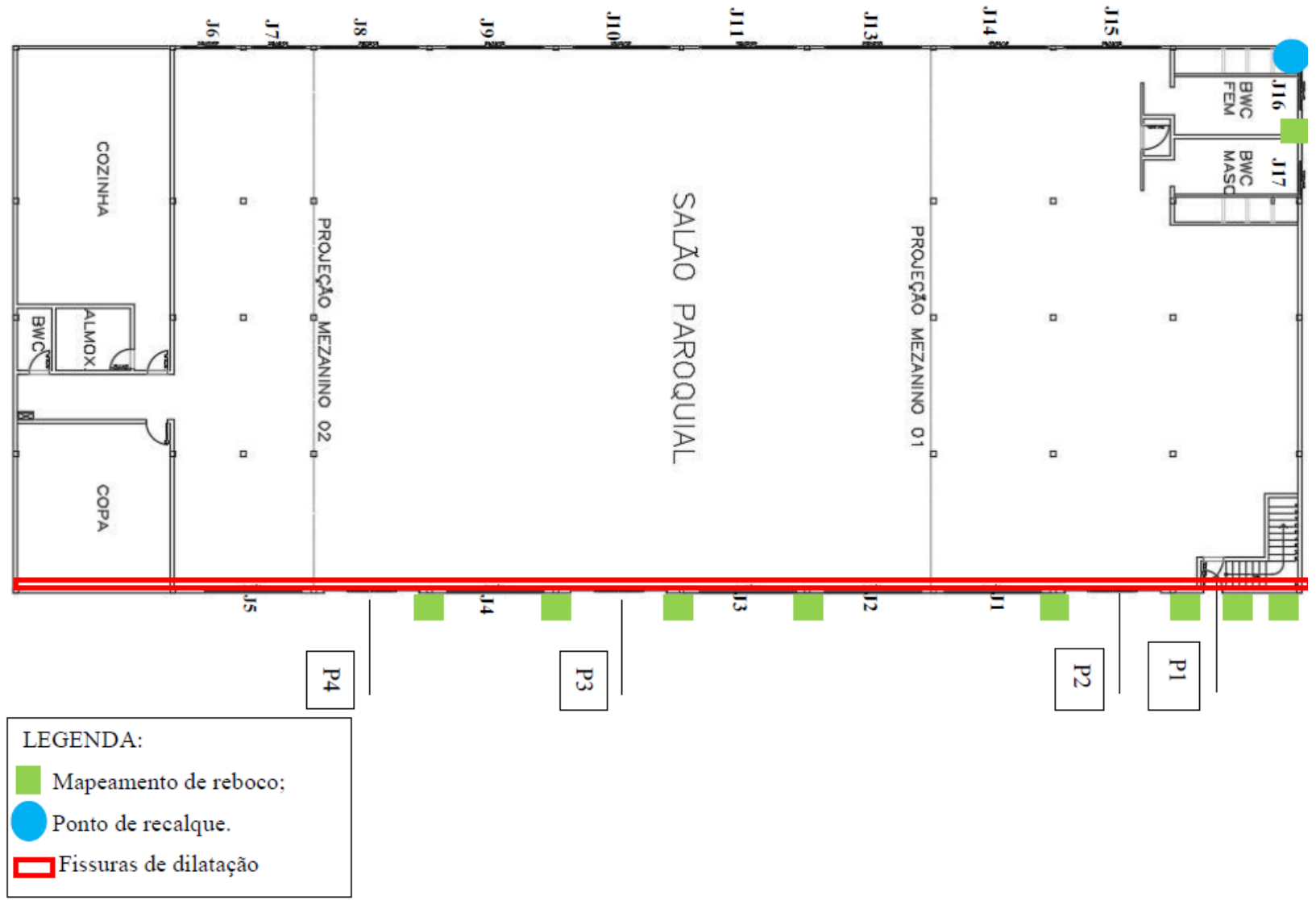

Figura 4: Mapeamento dos problemas patológicos identificados na edificação.

A maior parte das anomalias encontrava-se tangenciando os elementos estruturais como pilares e vigas, no entanto não afetavam a estrutura dos mesmos. De acordo com a metodologia adotada para classificação das anomalias, na Tabela 2 pode-se observar a ordem de prioridade de reparo das anomalias conforme matriz GUT.

Tabela 2 - Classificação das anomalias encontradas de acordo com a escala GUT

\begin{tabular}{ccccc}
\hline PROBLEMA & GRAVIDADE & URGÊNCIA & TENDÊNCIA & PRIORIDADE \\
\hline Fissuras devido ao recalque diferencial & 5 & 5 & 5 & 125 \\
\hline $\begin{array}{c}\text { Fissuras devido à dilatação térmica dos } \\
\text { materiais }\end{array}$ & 2 & 2 & 2 & 8 \\
\hline \begin{tabular}{c} 
Fissuras mapeadas (reboco) \\
\hline
\end{tabular} & 2 & 1 & 3 & 6 \\
\hline
\end{tabular}

De acordo com o descrito na metodologia, a análise foi realizada por meio da matriz GUT, na qual obteve-se que as fissuras provenientes de recalque diferencial possuem classificação 125 e necessitam de ação imediata, visto que podem agravar o caso rapidamente, encontrando-se em estado crítico.

\subsection{Recalque diferencial - fissuras}

As fissuras provenientes do recalque diferencial acompanham a extensão do pilar e descem diagonalmente ao sentido contrário ao ponto de recalque diferencial, conforme pode ser visualizado na Figura 5. 


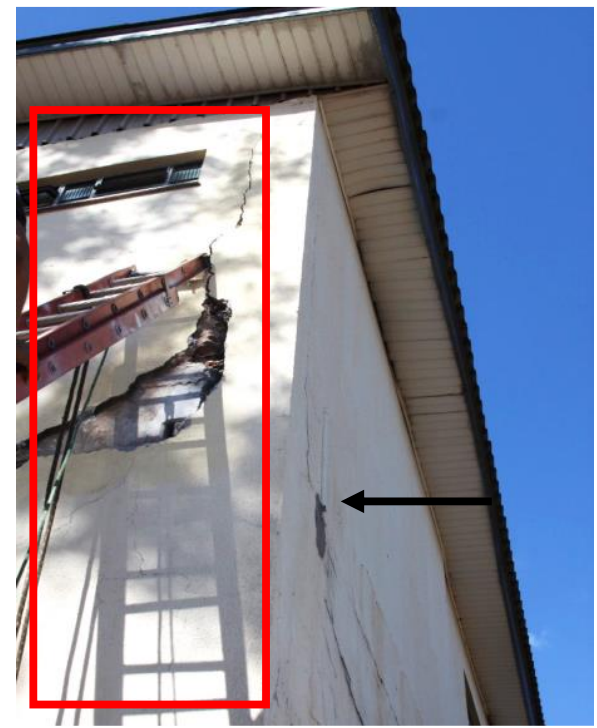

Figura 5: Fissuras e trincas causadas por recalque diferencial na fachada frontal e fachada lateral direita.

De acordo com a escala GUT, utilizada para classificação das anomalias quanto à ordem de prioridade de manutenção, as fissuras provenientes de recalque diferencial da fundação estão caracterizadas com prioridade 125 (cento e vinte e cinco). No caso da edificação em questão, a causa das fissuras provenientes de recalque diferencial da fundação se dá pela existência de uma fossa séptica na lateral da edificação, a qual, além de não estar em uso, não foi desativada de acordo com as normas específicas.

Além do exposto acima, o terreno possui declividade sentido ao muro, o qual não possui escoamento das águas pluviais e, quando na presença de chuvas torrenciais, gera um acúmulo de água no canto do muro, região próxima à fossa e ao ponto de recalque da edificação, conforme indicado na Figura 6.

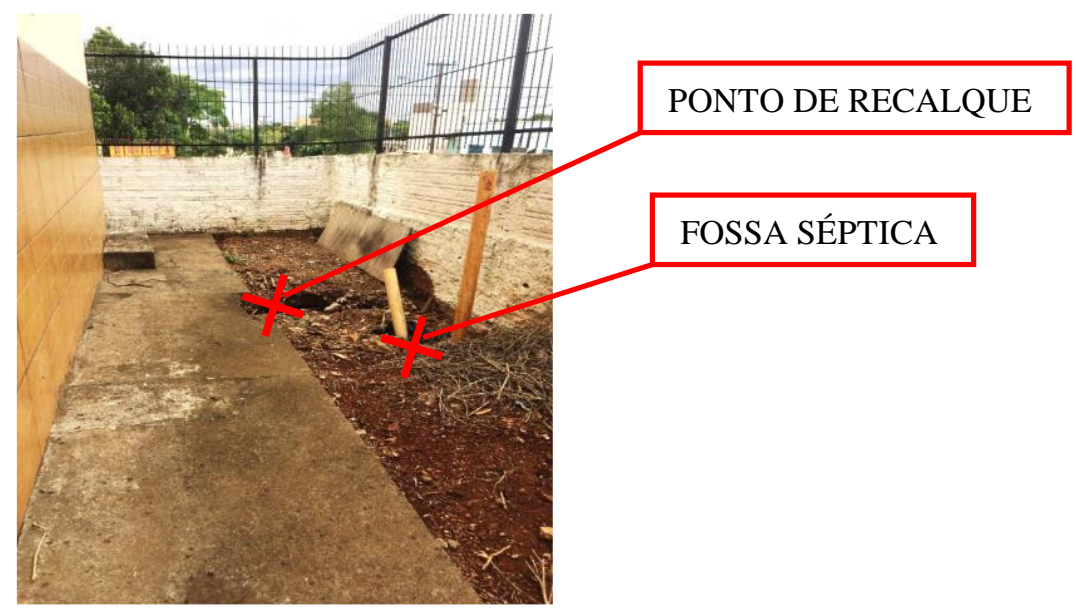

Figura 6: Localização do recalque e da fossa séptica.

Um fato aliado ao outro, ocasionou o carreamento do solo para dentro da fossa, gerando um alívio de tensões na região da fundação da edificação, o que ocasionou o recalque diferencial. De acordo com Thomaz (1989), o solo é constituído de partículas sólidas envoltas em água, ar e matéria orgânica, onde sob o efeito de cargas externas está suscetível a deformações diferenciadas caracterizadas como recalque, tal fato acarreta em manifestações patológicas que segundo Milititsky, Consoli e Schnaid (2015) é reconhecível devido à movimentação das fundações é a fissuração de elementos estruturais.

Além do exposto, a edificação não possui viga de fechamento, conforme pode ser visualizado na Figura 7, sendo que o elemento citado seria necessário para estabilidade global da edificação. 


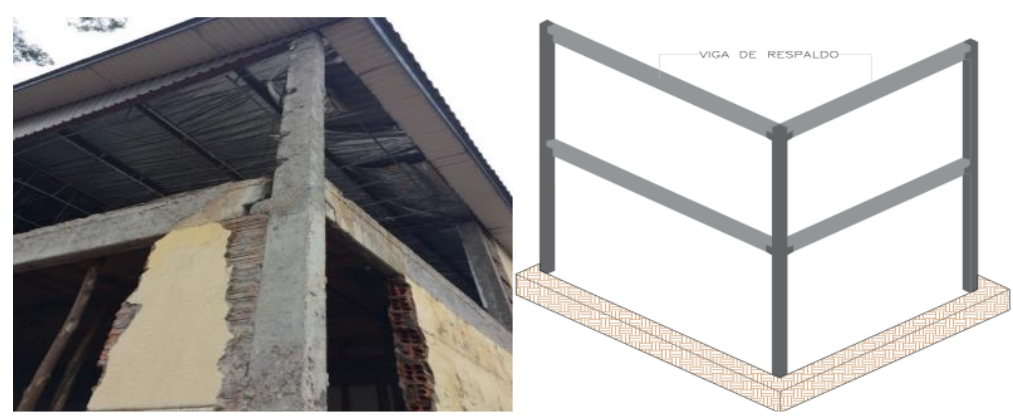

Figura 7: Evidência da ausência da viga de respaldo.

Tais anomalias têm origem em um possível erro de projeto e execução e para realizar o reparo da estrutura, sugere-se; primeiramente, a estabilização do ponto de recalque, item imprescindível para proceder com qualquer tipo de manutenção, pois de acordo com Thomaz (1989) é necessário avaliar a movimentação da estrutura e a recuperação somente poderá ser realizada após a paralisação total da movimentação de recalque da edificação.

Levando em consideração as circunstâncias em que a edificação se encontra, seria necessário aterrar a fossa séptica, para que o recalque não volte a ocorrer. Após aterramento da fossa, sugere-se a execução de um sistema de drenagem das águas pluviais, visto que a água costuma acumular no canto do lote, na junção entre os muros da fachada frontal e fachada lateral (direita).

Com a drenagem executada, seria necessário demolir as alvenarias externas (fachada frontal e fachada lateral direita), a fim de diminuir o peso exercido nos consolos que se encontram danificados. Com a demolição das alvenarias realizada, o próximo passo é a estabilização do ponto de recalque, por meio de reforço da fundação, no entanto, é imprescindível tomar cuidado com o tipo de fundação adotada, visto que não pode ocorrer vibração durante a execução, pois a edificação encontra-se em estado crítico.

Após a realização do reforço da fundação, sugere-se a inserção de consolos metálicos, para evitar a substituição total dos elementos estruturais danificados. O último passo do reparo é a execução da alvenaria, demolida para realizar os procedimentos.

\subsection{Ações para recuperação da estrutura}

A situação crítica de acordo com a escala GUT foi o ponto de recalque, na região de junção entre a fachada frontal e fachada lateral direita, onde a mesma obteve grau 125 (cento e vinte e cinco) e foi classificada com risco extremamente alto. Nesse caso, a interdição do local torna-se válida levando em consideração que a edificação estava em risco de ruína devido ao comprometimento dos elementos estruturais como pode ser observado na Figura 8.

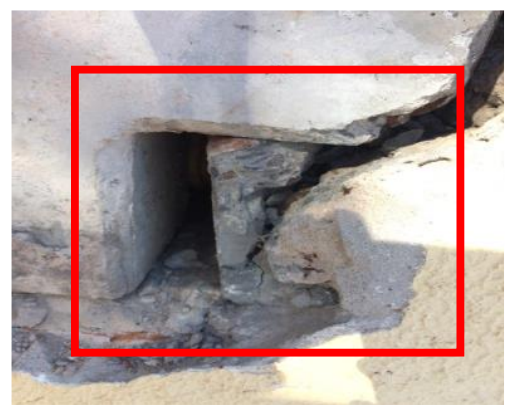

Figura 8: Estado crítico da estrutura do consolo do pilar.

A proposta de reparo sugerida pelo presente trabalho foi acatada pelos responsáveis pela edificação e executada sendo supervisionada por um Engenheiro Civil. Para melhor entendimento, a descrição das ações de intervenção foi dividida em 13 (treze) etapas, sendo estas descritas na sequência.

Inicialmente realizou-se o aterramento da fossa séptica que estava em desuso, pois a mesma encontrava-se a menos de dois metros da fundação comprometida da edificação e contribuía diretamente para o acontecimento do recalque diferencial. 
A segunda etapa referiu-se à demolição da alvenaria dos muros e das paredes internas e externas da região interditada, com a finalidade de diminuir a carga exercida sobre a fundação. A demolição da alvenaria foi um item importantíssimo realizado, pois as paredes exerciam um peso sobre os consolos dos pilares pré-moldados que se encontravam comprometidos.

O pilar de canto encontrava-se desalinhado, tombando para o lado de fora da edificação, devido à ausência de viga de fechamento. Ainda com as alvenarias demolidas, realizou-se o realinhamento dos pilares por meio de tirantes metálicos. Os quais permaneceram nos pilares até o reforço da fundação ser executado (Figura 9).

Após isso foi realizado o escoramento da laje por meio de escoras de eucalipto, que foi necessário a fim de evitar que a laje cedesse, visto que as vigas seriam posteriormente erguidas por meio de macacos mecânicos. Realizou-se assim o escoramento das vigas por meio de escoras metálicas (Figura 9) para evitar a torção dos elementos de concreto prémoldado. O escoramento realizado tanto na laje, por meio de escoras de eucalipto, quanto nas vigas, por meio de escoras metálicas, foi necessário a fim de evitar que a laje cedesse e as vigas sofressem momento torsor, levando em consideração a posterior suspensão da estrutura da edificação, por meio de macacos mecânicos.
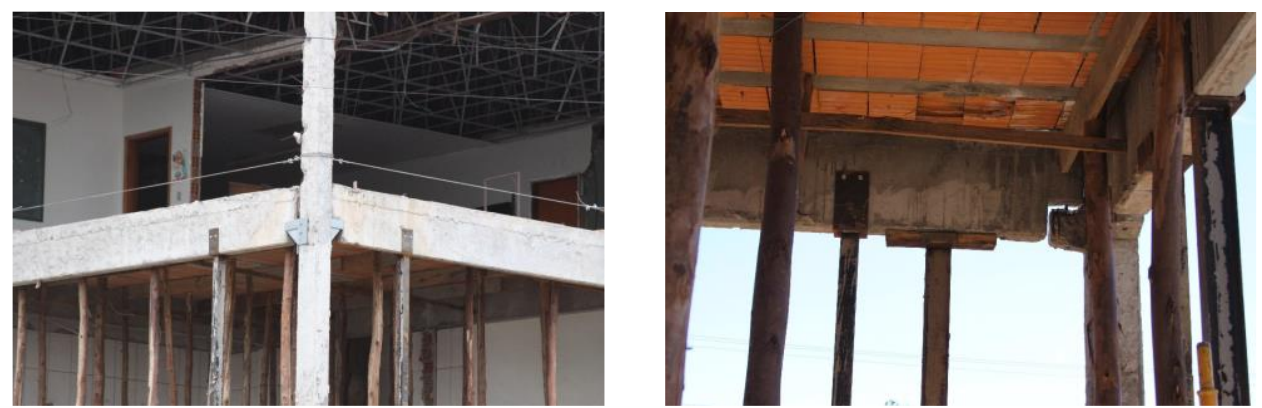

Figura 9: Atirantamento do pilar de canto e escoramento das vigas e laje.

Após a execução do escoramento, foi realizada a escavação do solo e preparação do mesmo para receber o reforço da fundação. Realizou-se a demolição dos muros por meio de retroescavadeira e também a escavação do solo, a fim de encontrar a fundação e repará-la.

Para a recuperação da fundação, optou-se pela execução de uma estaca mega para reforço da fundação existente, tanto escavação quanto concretagem do bloco. A estaca mega foi realizada em total acordo com a NBR 6122/2010, por empresa habilitada e reconhecida na cidade de Cascavel - PR e região. A estaca foi cravada no solo por meio de macaco hidráulico, com mínima vibração, contribuindo para a integridade da estrutura em sua totalidade. Tal procedimento pode ser observado na Figura 10.
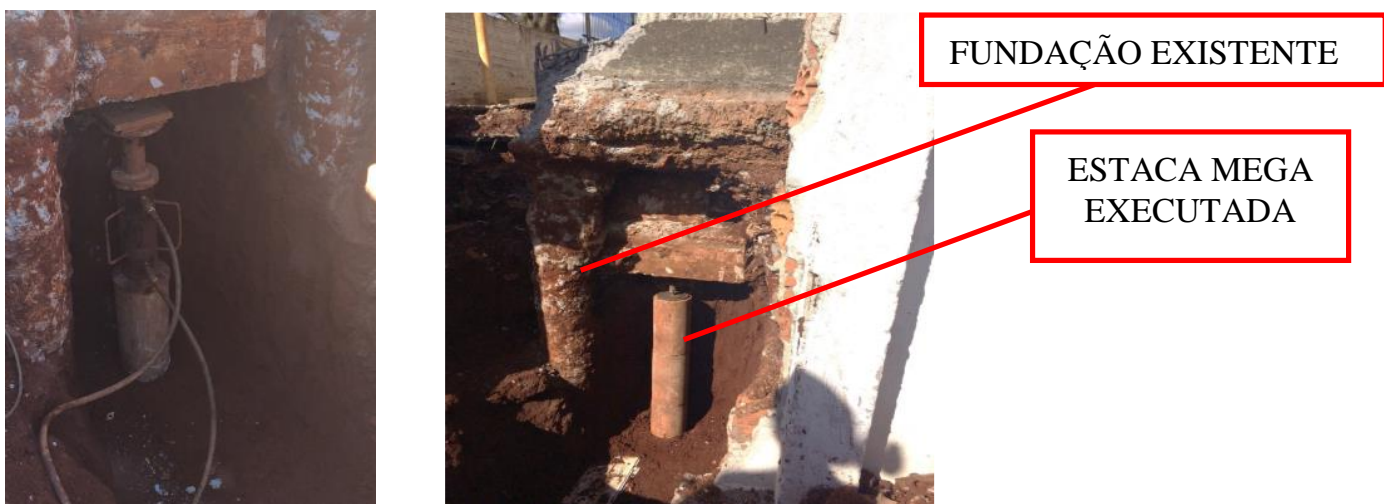

Figura 10: Estaca mega sendo executada para reforço da fundação.

Realizou-se o realinhamento da laje da estrutura, com a utilização de macacos mecânicos, a fim de erguer a laje que cedeu 4 (quatro) centímetros. Após a concretagem do bloco da estaca e seu respectivo período de cura, foi executado o nivelamento da laje, por meio de macacos mecânicos, com o auxílio de escoras metálicas, fabricadas na medida certa para o escoramento entre a viga intermediária e o macaco mecânico, o qual encontrava-se apoiado na viga baldrame. 
A nona etapa referiu-se à execução dos consolos metálicos para substituição dos consolos pré-moldados que se encontravam degradados. Os consolos existentes foram demolidos, pois já não exerciam sua função estrutural necessária aos esforços solicitantes da presente edificação. A laje e as vigas encontravam-se escoradas e os pilares atirantados quando foram executados os consolos metálicos, conforme pode ser observado na Figura 11.

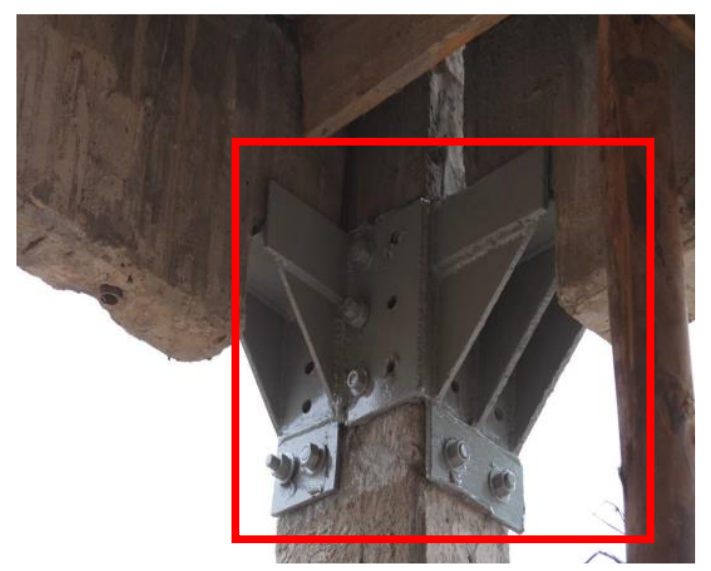

Figura 11: Substituição dos consolos existentes por consolos metálicos.

A décima etapa referiu-se à execução das vigas de fechamento, após retirar as escoras da edificação, foram executadas as vigas de fechamento na região de junção entre a fachada frontal e fachada lateral direita.

Executou-se então paredes em drywall na região interna da laje, devido ao peso específico das paredes em gesso acartonado ser inferior ao da alvenaria. As paredes internas da região afetada foram demolidas, a fim de diminuir o peso exercido sobre a fundação e dos elementos estruturais comprometidos. Optou-se por executar paredes de divisórias para as salas de aula e banheiros do mezanino 1 em gesso acartonado, também executados por empresa especializada e reconhecida na cidade de Cascavel - PR e região.

Após isso, a alvenaria de fechamento convencional foi executada por profissionais da construção civil contratados e acompanhada pelo Engenheiro Civil supervisor da edificação, responsável pela execução da recuperação.

A etapa final de recuperação referiu-se à execução do chapisco, emboço, reboco, pintura (acabamentos em geral). Os itens necessários para a execução dos acabamentos da alvenaria foram executados pela mesma equipe que executou as paredes em drywall. Pôde-se acompanhar a execução dos acabamentos de reboco, conforme ilustrado na Figura 12.

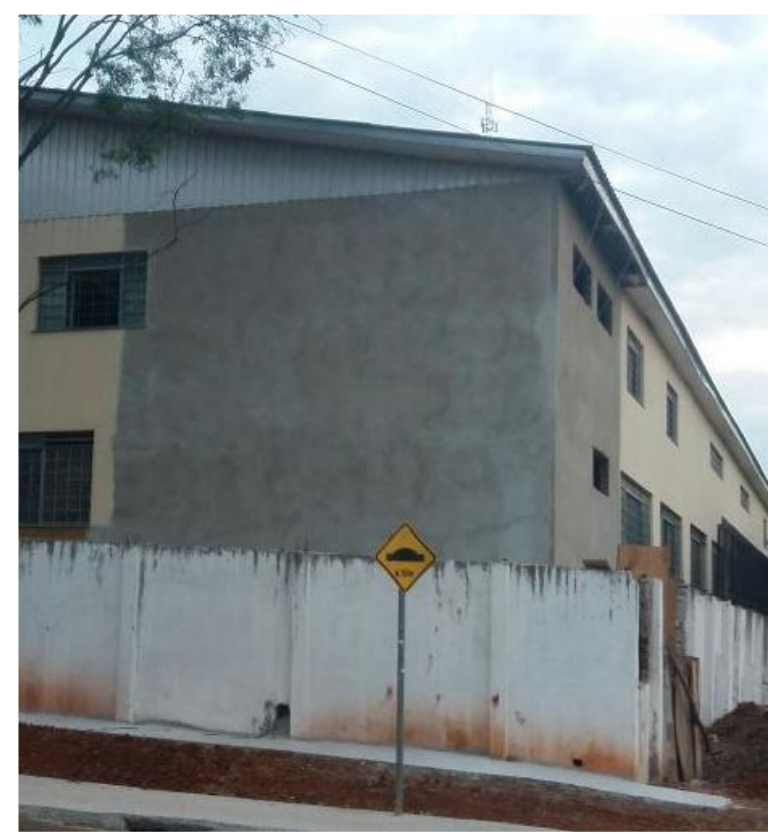

Figura 12: Alvenaria de fechamento finalizada. 


\subsection{Frequência das manifestações patológicas da edificação}

Na Figura 13 pode-se observar o gráfico de frequência das manifestações patológicas mapeadas na edificação.

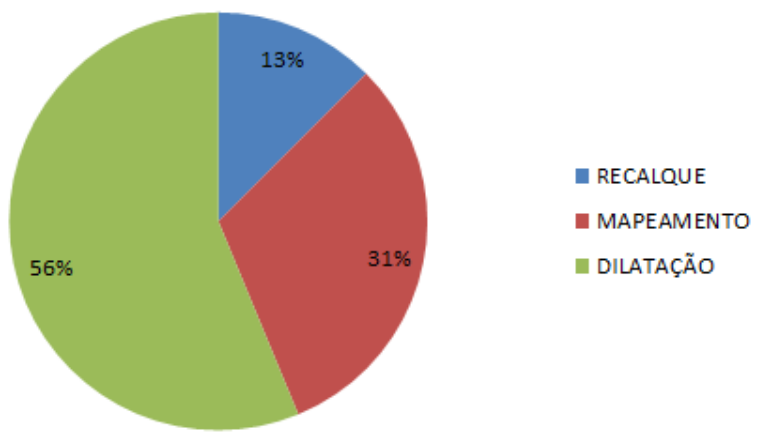

Figura 13: Gráfico de frequência das manifestações patológicas identificadas.

Por meio do gráfico observa-se que as anomalias de maior incidência são as fissuras mapeadas e as fissuras provenientes de dilatações térmicas/higroscópicas. Aquelas provenientes de recalque diferencial foram classificadas como extremamente grave, de acordo com a escala GUT. No entanto, a incidência das manifestações patológicas não resume a gravidade das mesmas.

Observam-se, ainda na Figura 12, as porcentagens obtidas no presente trabalho, onde as anomalias ocasionadas por dilatação dos materiais abrangem $56 \%$ do total das manifestações patológicas encontradas no local. Já as anomalias caracterizadas pelas fissuras mapeadas, compreendem $31 \%$ do total e as provenientes de recalque diferencial ocupam $13 \%$ de todas as manifestações patológicas encontradas na edificação. Tais anomalias são responsáveis pela menor porcentagem em relação à incidência das mesmas na edificação, no entanto são caracterizadas por oferecer um grau de risco elevado à edificação, conforme escala GUT.

\section{CONSIDERAÇÕES FINAIS}

Com base nos dados obtidos neste trabalho, conclui-se que a principal causa da interdição do local foi a ocorrência do recalque diferencial devido à existência da fossa séptica em desuso, porém não desativada de maneira correta, acarretando o comprometimento na integridade da estrutura, onde a mesma atingiu o seu ELU.

Além de fissuras na alvenaria, os elementos estruturais também sofreram outras manifestações patológicas, principalmente os consolos dos pilares pré-moldados. A estrutura da alvenaria convencional sofreu deslocamento com a supraestrutura, devido à ocorrência do recalque diferencial.

A fim de identificar e quantificar as anomalias presentes na edificação, foi realizado o mapeamento das anomalias em planta baixa em que as anomalias com maior incidência, ou seja, que mais se manifestaram na edificação, são as de menor gravidade quanto à escala GUT, sendo elas fissuras provenientes de dilatação dos materiais, ocupando uma porcentagem de $56 \%$ das anomalias identificadas no local e de mapeamento do revestimento argamassado, as quais são caracterizadas por $31 \%$ das manifestações patológicas existentes na edificação.

O salão paroquial possui um ponto de recalque, o qual é responsável por $13 \%$ das manifestações existentes no local, sendo ele na junção entre a fachada frontal e a fachada lateral direita. No entanto, um ponto de recalque causou maiores danos à estrutura da edificação e levou à interdição da mesma, do que as manifestações patológicas de maior incidência como as fissuras mapeadas em praticamente toda a fachada lateral esquerda.

A proposta de recuperação sugerida visou a estabilização total das movimentações provenientes de recalque e integridade da supraestrutura, onde preservou-se os elementos estruturais existentes, por meio de alívio de cargas provocados pela alvenaria e, somente após a execução de todo o reparo, a alvenaria de fechamento foi novamente executada. 


\section{AGRADECIMENTOS}

Os autores gostariam de agradecer a todos que colaboraram para o desenvolvimento desse trabalho. Isso inclui aqueles que fizeram doações para a execução da recuperação da estrutura, visto que se tratava de uma edificação de uso público. Além disso, pode-se destacar o trabalho do Centro Universitário Assis Gurgacz, da cidade de Cascavel-PR no desenvolvimento da pesquisa.

\section{REFERÊNCIAS}

FONSECA, J. J. S. Metodologia da pesquisa científica. Fortaleza: UEC, 2002.

GOLDENBERG, M. A arte de pesquisar: Como fazer pesquisa qualitativa em Ciências Sociais. 12. ed. Rio de Janeiro: RECORD, 2011.

GOMIDE, T. L. F.; FAGUNDES, J. C. P. N.; GULLO, M. A. Engenharia diagnóstica em edificações. 2. ed. São Paulo: PINI, 2015.

HELENE, P. R. L. Manual para reparo, reforço e proteção de estruturas de concreto. 2. ed. São Paulo: PINI, 1992.

KEPNER, C.; TREGOE, B. O Novo Administrador Racional. 1. ed. São Paulo: MAKRON BOOKS, 1991.

THOMAZ, E. Trincas em edifícios: causas, prevenção e recuperação. 1. ed. São Paulo: PINI, 1989.

SOUZA, V. C. M.; RIPPER, T. Patologia, recuperação e reforço de estruturas de concreto. 1. ed. São Paulo: PINI, 1998. 